\title{
Extracellular matrix components in bronchoalveolar lavage fluid in quartz exposed rats
}

\author{
Anders Eklund, Göran Tornling, Eleonora Blaschke, Tore Curstedt
}

\begin{abstract}
To investigate the long term effects of quartz, bronchoalveolar lavage (BAL) and analysis of lung silica were performed in rats $(n=20)$ one, four, and 12 months after exposure to intratracheally instilled crystalline silica. Total and relative concentrations of silica in the lungs were highest one month after exposure. At this time BAL fluid concentrations of total cells, macrophages, and lymphocytes increased five to 10 -fold compared with saline instilled controls $(n=19)$. The number of polymorphonuclear cells (PMNs) increased about 200-fold. The increased number of PMNs persisted during the year. Furthermore, albumin and fibronectin concentrations increased continually during the year, about two to fivefold the values of controls. Hyaluronan, by contrast, increased during the four month period (about eightfold) but decreased after one year to the one month concentration. Phospholipids in BAL fluid, raised already after one month, remained high at one year. The findings suggest progressive damage of the alveolar and interstitial tissues. Moreover, the increases in components of the extracellular matrix capable of building fibrotic networks are in agreement with the microscopical findings of fibrosis. Because only total cells, macrophages, and albumin concentrations correlated weakly with the silica contents of the lung, it is unlikely that the relation between quartz burden and the reaction in the lung is simple.
\end{abstract}

Inhalation of silica dust may cause a chronic inflammatory process that can progress to overt clinical silicosis. ${ }^{1}$ The character of the inflammation that subsequently leads to fibrosis and impairment of lung function has been studied in both human subjects

Department of Thoracic Medicine

A Eklund, G Tornling

Department of Clinical Chemistry, Karolinska Hospital, Stockholm, Sweden

E Blaschke, T Curstedt and animals. ${ }^{2-8}$ It was earlier believed that the inflammation and tissue damage caused by inhalation of silica particles were due to the rupture of phagolysosomal membranes with subsequent release of enzymes from alveolar macrophages (AMs) that had ingested the particles. ${ }^{9}$ This toxicity seems, however, to be more prominent in vitro than in vivo. ${ }^{3}$ At present a more generally accepted theory is that the silica activated AMs exert pro-inflammatory effects on alveolar lymphocytes and neutrophils and stimulate lung fibroblasts to increase collagen and non-collagen protein synthesis. ${ }^{410}$ A type II cell hyperplasia develops after exposure and type II alveolar epithelial cells may occur in the bronchoalveolar lavage (BAL) fluid. ${ }^{11}{ }^{12}$ Also, BAL fluid of quartz exposed animals contains lipoproteins and lipids similar to surfactant. ${ }^{5713}$

Alveolitis caused by silica has been studied with BAL in human subjects ${ }^{23}$ and in animals, mainly rats, ${ }^{4-6}$ sheep, ${ }^{7}$ and guinea pigs. ${ }^{8}$ After exposure to quartz either via a single intratracheal instillation or by inhalation of silica dust, pronounced increases of all alveolar cell populations were found as well as increased concentrations of albumin, fibronectin, and glycosaminoglycans. We found increased hyaluronan concentrations in rats four months after exposure. ${ }^{6}$ Except for a few studies by Bégin's group, however, the follow up periods after exposure were short, from about two to 16 weeks.

To evaluate the long term effect of exposure to quartz, we investigated in the present study the time dependence of the inflammatory and fibrotic responses in rats during one year using the BAL technique. The intensity of the inflammatory and fibrotic reaction was estimated by measuring markers such as cell numbers, and albumin, hyaluronan, fibronectin, and phospholipid concentrations. We also attempted to relate the changes to the silica burden present in the lungs.

\section{Materials and methods}

PREPARATION OF CRYSTALLINE SILICA

Crystalline silica containing $98.3 \%$ quartz was prepared from natural sand by sedimentation in water. The mean diameter of the particles was $1.2 \mu \mathrm{m} ; 90 \%$ had a diameter of less than $3 \mu \mathrm{m}$. The particles were resuspended in physiological saline until a concentration of $40 \mathrm{mg} / \mathrm{ml}$ was obtained. 


\section{ANIMAL EXPERIMENTS}

Thirty nine female Sprague Dawley rats were included in the study. Under shallow ether anaesthesia a cannula was passed through the mouth into the trachea via the larynx with the rats fixed in a semiupright position. In 20 of the rats, $1.0 \mathrm{ml}$ of the silica suspension was rapidly injected into the trachea. In the other 19 animals, which served as controls, $1.0 \mathrm{ml}$ of sterile physiological saline was instilled.

The study was approved by the local ethics committee.

\section{BRONCHOALVEOLAR LAVAGE (BAL)}

Bronchoalveolar lavage was performed as previously described. ${ }^{6}$ Briefly, the animals were killed by inhalation of ether and the tracheas were cannulated. Hank's balanced salt solution at $37^{\circ} \mathrm{C}$ was infused into the lungs in aliquots of $5 \mathrm{ml}$ at a hydrostatic pressure of $20 \mathrm{~cm} \mathrm{H}_{2} \mathrm{O}$. After three minutes the fluid was drained by gravity into a siliconised tube placed on ice. The procedure was repeated 10 times up to a total of $50 \mathrm{ml}$ applied solution. The recovery of the instilled fluid was 86.0 (SD 9.4 )\% in controls and $87 \cdot 8$ (SD $11 \cdot 4) \%$ in quartz exposed rats.

\section{HANDLING OF BAL FLUID}

Cells were pelleted at $400 \mathrm{~g}$ for five minutes at $4^{\circ} \mathrm{C}$ and resuspended in $5 \mathrm{ml}$ of Hank's solution. A total cell count was carried out in a Bürker chamber. Cell viability was determined by Trypan blue exclusion. A differential cell count was done on cytocentrifugal smears prepared in a Cytospin 2 apparatus (Shandon, Southern Products Ltd, Runcorn, England) at $\mathbf{5 0 0}$ $\mathrm{rev} / \mathrm{min}$ for three minutes. Cells were stained according to May-Grünwald Giemsa and 500 cells were counted. The supernatant liquid was stored at $-70^{\circ} \mathrm{C}$ until analysis.

\section{BIOCHEMICAL ANALYSES IN BAL FLUID}

Albumin was determined by rocket immunoelectrophoresis. ${ }^{14}$ Rat albumin and rabbit anti-rat albumin antibodies (Nordic Immuno-chemical Lab, Tilbury, The Netherlands) were used as standard and antiserum respectively.

Fibronectin was assayed by a double sandwich enzyme linked immunosorbent assay (ELISA). ${ }^{15}$ Serum fibronectin of nephelometric quality from Behring-Hoechst (Frankfurt am Main, Germany) was used as a standard. Because human fibronectin and antibodies against human antigen were used, the BAL fluid concentrations of fibronectin in the rat may not be "true" values. They are well suited, however, for comparing fibronectin concentrations between quartz exposed and control rats.

Hyaluronan was analysed in principle according to Engström-Laurent et $a l^{16}$ using the Pharmacia HA

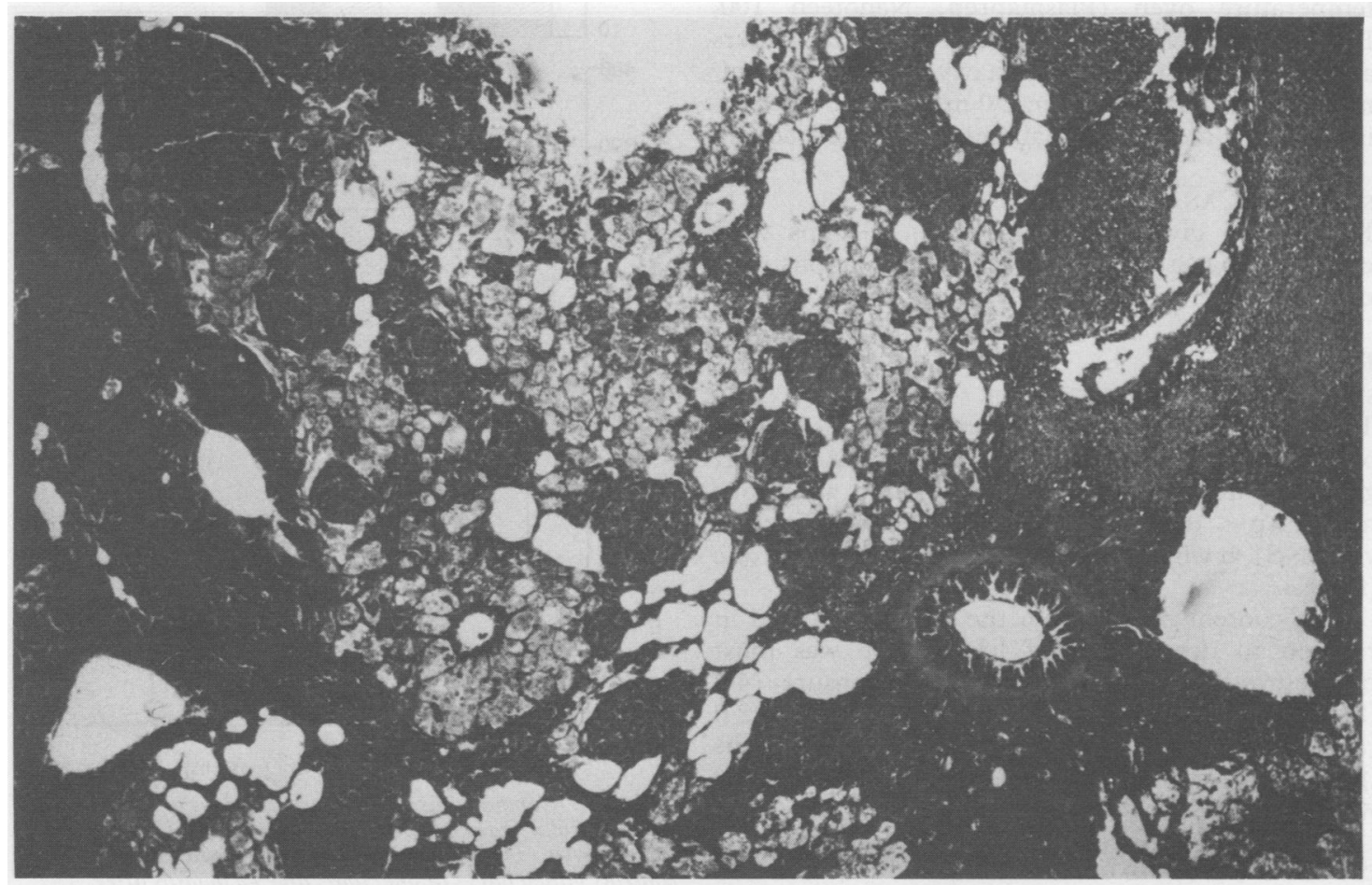

Figure 1 Light microscopy of lung tissue one year after the exposure to quartz showing pronounced fibrotic changes. 
test kit (Pharmacia, Uppsala, Sweden). Because human antigen was used, the same caution is valid as for fibronectin.

\section{ANALYSES OF PHOSPHOLIPIDS}

The contents of phosphatidylcholine and of the surface active 1,2-dipalmitoyl-phosphatidylcholine were determined as previously described. ${ }^{17}$ Briefly, the lung lobes were homogenised at $4^{\circ} \mathrm{C}$ and extracted with 19 volumes of chloroform:methanol, 2:1 $(\mathrm{v} / \mathrm{v})$. After filtration 0.2 volumes of water containing $0.58 \% \mathrm{NaCl}$ were added and the lower phase was taken to dryness and weighed.

The phospholipids were isolated by reverse phase chromatography on a column of Lipidex-5000. After fractionation into non-acidic and acidic phospholipids by chromatography on a lipophilic anion exchanger, the different classes of phospholipids were isolated by thin layer chromatography. The concentration and composition of phospholipids were determined by phosphorus analysis. ${ }^{18}$ The phosphatidylcholines were hydrolysed with phospholipase $C$ and the 1,2-diacylglycerols formed were analysed as trimethylsilyl ethers by capillary gas liquid chromatography.

\section{ANALYSIS OF QUARTZ CONTENT}

The lungs were cut into pieces and dried for 48 hours at $60^{\circ} \mathrm{C}$. The dry pieces were ashed in a low temperature oven (Plasmaprep, Nanotech 100, Birmingham, UK) with an effect of $40 \mathrm{~W}$ for 24 hours and $100 \mathrm{~W}$ for 24 hours and an oxygen flow of $13 \mathrm{ml} /$ min. The quartz content in $2.0 \mathrm{mg}$ of the homogenised ashed material was analysed by $x$ ray diffraction.

\section{STATISTICAL ANALYSIS}

Results are given as means (SD). Groups were compared by Student's $t$ test and correlations were calculated by regression analysis.

\section{Results}

SILICA CONTENT IN LUNG TISSUE

The total content of quartz in lung tissue was highest one month after exposure (24.3 (SD 5.7) $\mathrm{mg} \mathrm{SiO}_{2}$ ). It gradually declined to 17.4 (SD 4.4 ) $\mathrm{mg}$ after four months (p < 0.05) and to 12.6 (SD 7.0) $\mathrm{mg}$ after one year (NS), at which time the lung had become fibrotic (fig 1).

The content of quartz in the lungs expressed in relation to dry weight of lung tissue was most pronounced one month after the exposure (4.9 (SD 0.9)) $\mathrm{mg} \mathrm{SiO}_{2} / \mathrm{g}$ dry weight. It decreased to 2.0 (SD 0.3$) \mathrm{mg} \mathrm{SiO}_{2} / \mathrm{g}$ dry weight after four months $(\mathrm{p}<0.001)$ and to $0.84(\mathrm{SD} 0.3) \mathrm{mg} \mathrm{SiO}_{2} / \mathrm{g}$ dry weight after 12 months $(\mathrm{p}<0.001)$.

\section{CELLULAR BAL FLUID COMPONENTS}

The total cell concentration in the BAL fluid of quartz exposed rats was about seven times higher than in controls after one month $(p<0.001)$ (fig $2 \mathrm{~A})$. The differences decreased with time, to about fivefold the values of controls $(p<0.01$ and $p<0.05$ for four and 12 months respectively). The total cell concentrations of the quartz exposed rats were significantly lower after 12 months than after one month $(p<0.05)$. A slight but significant decrease in total
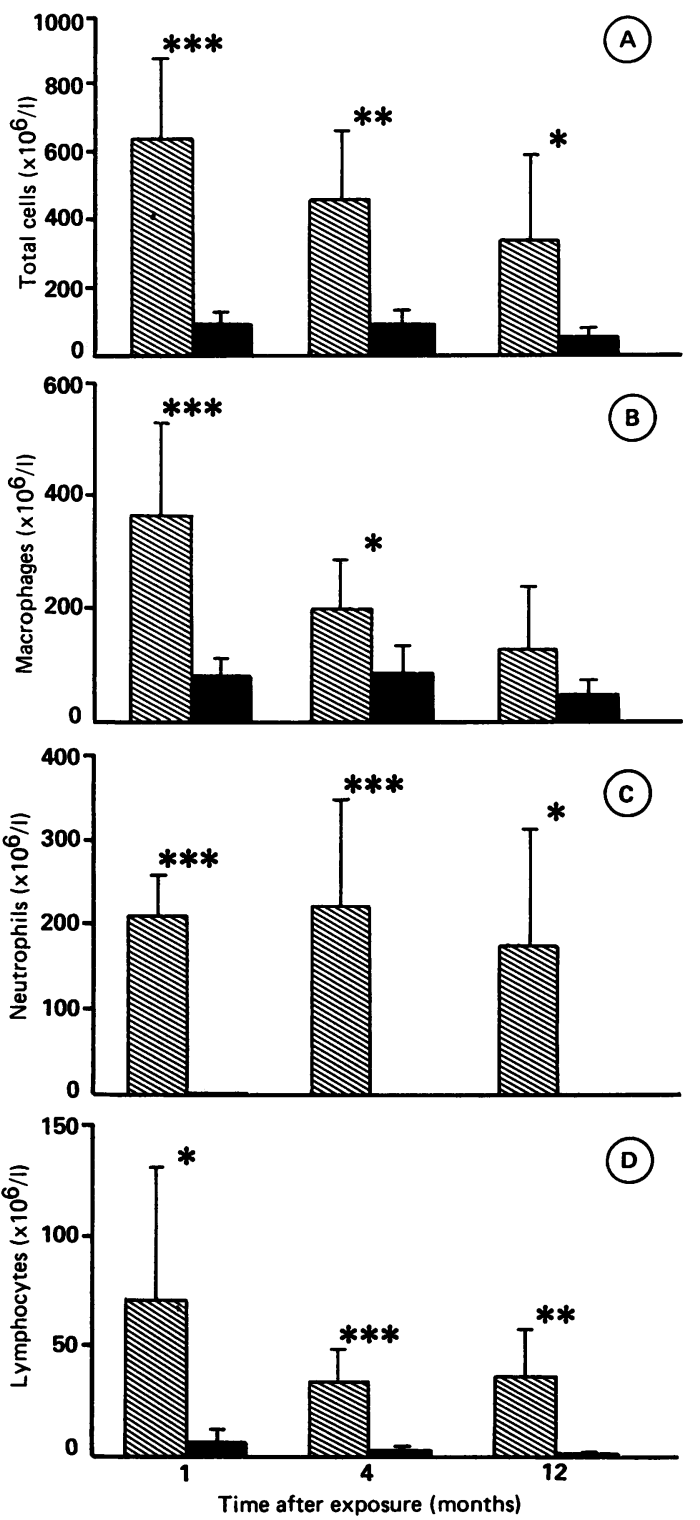

Figure 2 Comparisons of the concentrations of total cells $(A)$, alveolar macrophages (B), neutrophils (C), and lymphocytes (D) in quartz exposed rats (hatched bars) and controls (filled bars) at one, four, and 12 months after exposure. ${ }^{\star} p<0.05 ;{ }^{\star \star} p<0.01 ;{ }^{\star \star \star} p<0.001$. 
cell concentration of controls was found between the first and twelfth as well as between the fourth and twelfth months ( $p<0.05$ for both).

Cell viability did not differ between control and quartz exposed rats, with values of 95.5 (SD 4.7$) \%$ and $92 \cdot 2$ (SD 6.5$) \%$ respectively.

Also, the concentration of alveolar macrophages showed a pronounced (about fivefold) increase in quartz exposed animals after one month compared with controls ( $p<0.001$ ) (fig 2B). The differences decreased with time after exposure and were not statistically significant after one year. Similarly (fig 2D), the concentration of lymphocytes differed $(p<0.05)$ after one month, with about ten times more cells in the quartz exposed rats than in controls: large variation was found between rats (this was not due to methodological error as the identity of the cells was checked with a macrophage specific esterase staining). In the quartz exposed animals, the concentrations of lymphocytes decreased somewhat after four months but not later. The significant differences between quartz exposed and control rats persisted throughout.

The exposure to quartz had the most pronounced effect on the concentration of polymorphonuclear cells (PMNs) (fig 2C). After one month, the increase was about 200-fold ( $p<0.001$ ) compared with controls. The high concentrations of PMNs and their marked differences compared with controls persisted throughout the 12 month period.

\section{SOLUBLE BAL FLUID COMPONENTS}

\section{ALBUMIN}

The concentration of albumin in the BAL fluid of quartz exposed rats was significantly higher than in controls (fig 3A). The albumin concentration of the quartz exposed rats increased with time from about twofold to about fivefold of control values and was significantly higher $(p<0.05)$ after 12 months than after one month.

\section{FIBRONECTIN}

The concentrations of fibronectin in the BAL fluid had increased after one month in the quartz exposed rats to about twofold of controls ( $p<0.001$ ) (fig 3B). They increased still more by four months, to about three to fourfold of controls ( $p<0.01$ both compared with controls and one month values respectively). The concentration at 12 months was similar to that at four months ( $p<0.001$ compared with controls and one month values respectively).

\section{HYALURONAN}

The concentration of hyaluronan had increased significantly $(p<0.001)$ in the quartz exposed animals by one month after exposure to about threefold of control values (fig 3C). A further increase had occurred after four months to about seven to eight- fold control values. Twelve months after exposure, however, the hyaluronan concentrations had decreased to values similar to the one-month concentrations, although they still differed significantly $(p<0.001)$ from controls. The pronounced increase in hyaluronan concentrations after four months differed significantly from those at one and 12 months ( $\mathrm{p}<0.01$ and $\mathrm{p}<0.001$ respectively).

\section{PHOSPHOLIPIDS}

The contents of phospholipids in the quartz exposed rats $(\mathrm{n}=5$ ) were 24.1 (SD 5.2) $\mu \mathrm{mol} / \mathrm{g}$ lung tissue after one month, which was significantly $(p<0.01)$ higher than in controls $(\mathrm{n}=5,13.3$ (SD 4.2) $\mu \mathrm{mol} /$ g). At one year the concentrations in exposed $(n=5)$ and control $(\mathrm{n}=5)$ rats were $37.2(\mathrm{SD} 15.4) \mu \mathrm{mol} / \mathrm{g}$ and $10 \cdot 1(\mathrm{SD} 1 \cdot 1) \mu \mathrm{mol} / \mathrm{g}$ respectively. No significant difference was found between the exposed animals
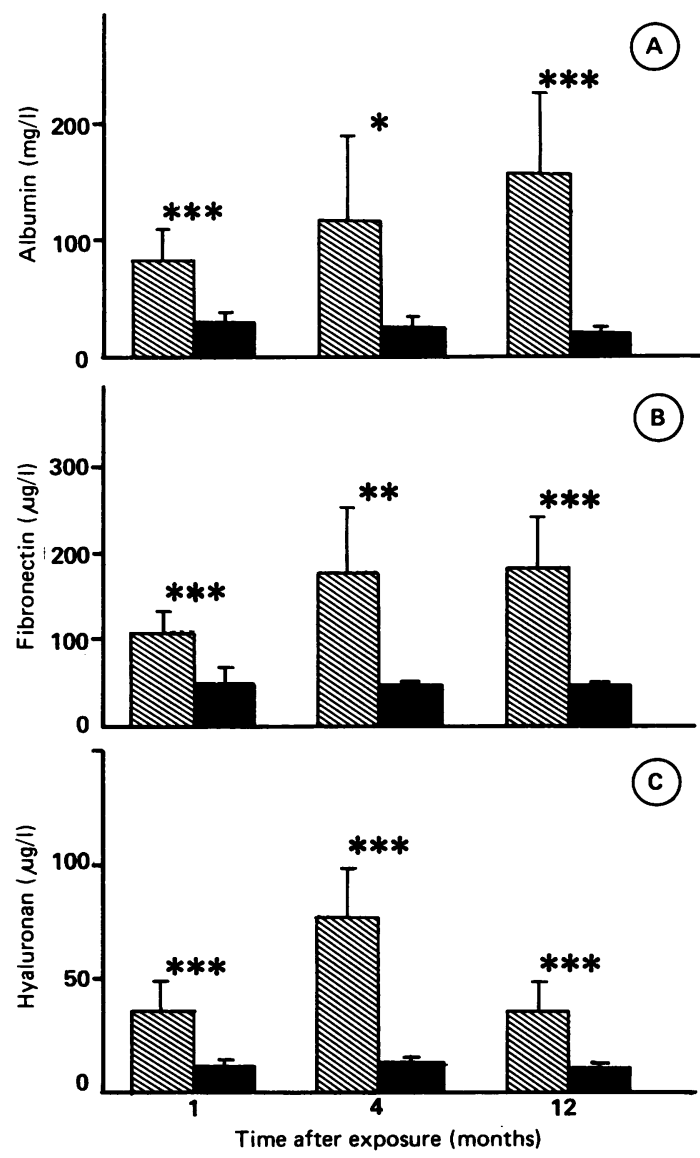

Figure 3 Comparisons of the concentrations of albumin $(A)$, fibronectin $(B)$, and hyaluronan $(C)$ in quartz exposed rats (hatched bars) and controls (filled bars) at one, four, and 12 months after exposure. ${ }^{\star} p<0.05 ;{ }^{\star \star} p<0.01$, $\star \star \star p<0.001$. 
after one and 12 months. The content of phosphatidylcholine one year after exposure to quartz was $29 \cdot 3$ (SD 14.2) $\mu \mathrm{mol} / \mathrm{g}$ lung tissue compared with 5.8 (SD 1.4) $\mu \mathrm{mol} / \mathrm{g}$ in controls $(\mathrm{p}<0.001)$. The surface active 1,2 dipalmitoyl- phosphatidylcholine content at one year was 17.4 (SD 8.4) $\mu \mathrm{mol} / \mathrm{g}$ and 2.7 (SD 0.8$) \mu \mathrm{mol} / \mathrm{g}$ in the exposed $(\mathrm{n}=5)$ and control $(\mathrm{n}=5)$ rats respectively. The difference was significant $(\mathrm{p}<0.01)$.

\section{CORRELATIONS BETWEEN CELLS AND SOLUBLE} COMPONENTS OF BAL FLUID IN QUARTZ EXPOSED RATS No correlations were seen between the total cell concentration and the soluble componentsalbumin, fibronectin, and hyaluronan-at any of the time points. Similarly, the concentrations of AMs, neutrophils, and lymphocytes failed to show any correlations with these soluble substances.

\section{CORRELATIONS BETWEEN SOLUBLE COMPONENTS OF} BAL FLUID IN QUARTZ EXPOSED RATS

The concentrations of fibronectin and hyaluronan were significantly correlated one month $(r=0.89$, $\mathrm{p}<0.05)$, four months $(\mathrm{r}=0.88, \mathrm{p}<0.01)$, and 12 months $(r=0.76, p<0.05)$ after exposure to silica (fig 4A). Also, for all animals together the correlation between fibronectin and hyaluronan was significant $(r=0.60, p<0.005)$. As shown in fig 4B, the fibronectin concentration was also correlated to lavage albumin concentration when all animals were compared as a group ( $r=0.80, p<0.001)$.

No correlations were found between hyaluronan and albumin in the quartz exposed rats, or between any of the substances in the controls.

\section{CORRELATIONS BETWEEN CONCENTRATION OF LUNG}

SILICA AND ALVEOLAR CELLS

No significant correlations were found in the exposed animals between total cell concentrations and total amounts of silica in the lungs at any time or for the group as a whole. The total cell concentration, however, correlated $(r=0.50, p<0.05)$ with the silica ratio ( $\mathrm{mg} \mathrm{SiO} / \mathrm{g}$ dry weight) when all animals were compared. No correlation was found at each time point. The concentration of AMs correlated with the total silica content $(r=0.52, p<0.05)$ as well as with the silica ratio $(r=0.66, p<0.01)$ for all exposed rats but no correlations were found at the separate occasions. Neutrophils and lymphocytes were not correlated with the silica contents or with the silica ratios.

CORRELATIONS BETWEEN CONCENTRATION OF LUNG SILICA AND SOLUBLE COMPONENTS OF BAL FLUID The total amount of quartz in the lungs correlated with the concentration of albumin in the BAL fluid at four months $(r=0.77, p<0.05)$, but showed no other relation with albumin, hyaluronan, or fibro-
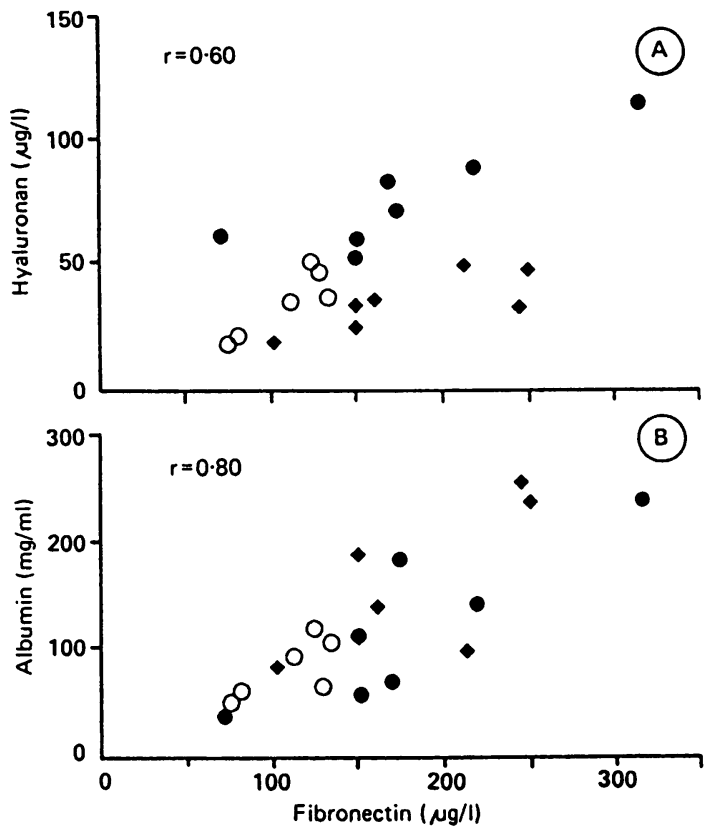

Figure 4 Correlations between soluble components of the lavage fluid in all rats exposed to silica (after one [O], four [ ], and 12 [ $\triangleleft$ months). A shows the correlation between hyaluronan and fibronectin and $B$ the correlation between albumin and fibronectin.

nectin concentrations. The silica ratio $(\mathrm{mg} \mathrm{SiO} / \mathrm{g}$ dry weight) of the lungs showed no correlations with any of the soluble components of the BAL.

\section{Discussion}

In the present study, after one month rats exposed to intratracheally instilled silica already showed considerable increases in numbers of alveolar cells and of soluble substances known to be accumulated at sites of inflammation. Subsequently, the intensity of the alveolitis subsided but distinct signs of changes in the alveolar environment still remained one year after exposure.

In accord with previous reports, ${ }^{1-3}$ the total alveolar cell concentration was much higher in the quartz exposed animals than in controls. The viability of the cells was not impaired. The increase in cell number concerned all alveolar cell populations. One month after exposure to silica it was most pronounced, about 200 -fold, for neutrophils. Davis et $a l^{1}$ have stressed the pro-inflammatory role that AMs may have after ingesting silica particles. The activated AMs are capable of releasing substances that in turn may initiate activity in other cell populations or accelerate the inflammatory process by the production of, for example, complement factors. Moreover, functional capacities, such as chemotactic 
ability, may be impaired. ${ }^{19}$ The AM population nearly normalised within a year, however, whereas lymphocyte and especially neutrophil concentrations remained appreciably raised. A predominance of $T$ helper cells during the initial phase ${ }^{20}$ indicates that lymphocytes may be most important in the early alveolitic phase of silicosis. On the other hand, the pronounced neutrophilia, persistent even after one year, may play a substantial part in lung tissue damage going on during the fibrotic phase, due to the ability of neutrophils to release proteolytic enzymes and free oxygen radicals.

The intensity of the alveolitis was also apparent in the raised concentration of albumin in the lavage fluid. Albumin diffuses to the alveolar space through the alveolar capillary membrane and the leakage is greatly enhanced in alveolar inflammatory processes..$^{21}$ The rise in albumin concentration increased with time, indicating a progressive damage of the alveolar capillary membrane. A severely damaged membrane may also allow the passage of fibronectin, although this may not pass through an intact membrane because of its size. This may explain the correlation found between albumin and fibronectin in the quartz exposed rats.

Fibronectin, shown to be released from macrophages, ${ }^{22}$ is a multifunctional glycoprotein. It may opsonise $^{23}$ alveolar debris for phagocytosis and has the ability to attract neutrophils. ${ }^{24}$ It functions as a chemotactic ${ }^{25}$ and growth factor ${ }^{26}$ for fibroblasts and may contribute to the adhesion, aggregation, migration, and organisation of cells in the alveolar space. Due to its many binding sites for substances such as fibrin, glycosaminoglycans, and collagen, it may also contribute to the build up of an extracellular network, the prerequisite of fibrosis. Thus, fibronectin may play an active, possibly even central, part in the ultimately developing fibrosis in the quartz exposed animals. It is tempting to speculate that it represents one of the procollagenic factors found by Benson et al. ${ }^{4}$

The glycosaminoglycan hyaluronan is known to be highly hydrated in vitro. Recently, Nettelbladt $e t \mathrm{al}^{27}$ showed that hyaluronan also has unique water immobilising properties in vivo. As previously discussed, hyaluronan may also, together with fibronectin, participate in the build up of the extracellular matrix, a prerequisite for the development of fibrosis. The high and parallel increases in fibronectin and hyaluronan concentrations especially during the initial period agree with such a function.

As mesenchymal cells are capable of synthesising hyaluronan, fibroblasts could be its possible source. On the other hand it has been suggested that epithelial cells may be the site of hyaluronan production as hyaluronan accumulates in the BAL fluid in bleomycin induced alveolitis. ${ }^{28}$ Our finding of high concentrations of hyaluronan in the lavage fluid of quartz exposed rats together with signs of enhanced secretory activity or damage to type II pneumocytes lends support to this latter hypothesis.

The phospholipid concentrations in the BAL fluid were already raised one month after exposure to silica. This could be due to an increased producton of phospholipids by type II cells or to an expanded cell mass. The finding of type II cells in the lavage fluid of quartz exposed subjects ${ }^{12}$ would agree with such a possibility. On the other hand impaired clearance could also contribute to the accumulation of phospholipids in the fluid.

The changes found in cell populations and the soluble components measured in the BAL fluid of quartz exposed rats indicate that the silica particles initiate an intense and long standing alveolar and interstitial inflammation. Only a few of the BAL components, however, such as total cells, macrophages, and albumin were correlated with silica content in the lungs. As the total content of silica in the lungs slowly decreased with time, the quartz particles were apparently eliminated from the lungs from about $5 \mathrm{mg}$ to $0.8 \mathrm{mg}$ per $\mathrm{g}$ lung tissue in 11 months. Despite diminishing silica contents several of the BAL fluid components increased with time. We suggest that the findings indicate that no simple "stoichiometric" relation between the quartz content and the extent of the reaction in the lung exists.

In conclusion, exposure to quartz in rats resulted in an intensive inflammatory process with signs of activation of alveolar and possibly interstitial cells. The activity slowly diminished but one year after exposure the lavage fluid still showed distinct signs of an ongoing process which probably reflects the development of fibrosis.

We thank Roine Hernbrand and Barbro Larsson, Karolinska Hospital, for excellent technical assistance. The staff at the Division of Aerosols at the National Institute of Occupational Health, Solna is also gratefully acknowledged. Grant support was from the Swedish Heart Lung Foundation and the Smedby Foundation.

Requests for reprints to: Anders Eklund, MD, Dept of Thoracic Medicine, Karolinska Hospital, S-104 01 Stockholm, Sweden

1 Davis GS. Pathogenesis of silicosis: current concepts and hypotheses. Lung 1986;164:139-54.

2 Bégin R, Cantin AM, Boileau RD, Bisson GY. Spectrum of alveolitis in quartz-exposed human subjects. Chest 1987; 92:1061-7.

3 Christman JW, Emerson RJ, Graham WGB, Davis GS. Mineral dust and cell recovery from the bronchoalveolar lavage of healthy Vermont granite workers. Am Rev Respir Dis 1985; 132:393-9.

4 Benson SC, Belton JC, Scheve LG. Regulation of lung fibroblast proliferation and collagen synthesis by alveolar macrophages in experimental silicosis. I. Effect of macrophage conditioned medium from silica-instilled rats. J Environ Pathol Toxicol Oncol 1986;7:87-97.

5 Dethloff LA, Gilmore LB, Gladen BC, George G, Chabra RS, 
Hook GE. Effects of silica on the composition of the pulmonary extracellular lining. Toxicol Appl Pharmacol 1986;84:66-83.

6 Tornling G, Eklund A, Engström-Laurent A, Hällgren R, Unge $\mathrm{G}$, Westman $\mathrm{B}$. Hyaluronic acid in bronchoalveolar lavage in rats exposed to quartz. $\mathrm{Br} J$ Ind Med 1987;44:443-5.

7 Bégin R, Dufresne A, Cantin A, et al. Quartz exposure, retention and early silicosis in sheep. Exp Lung Res 1989;15:409-28.

8 Sjöstrand M, Rylander R. Lysosomal enzyme activity and fibroblast stimulation of lung lavage from guinea pigs exposed to silica dust. Br J Exp Path 1987;68:309-18.

9 Allison AC, Harington JS, Birbeck M. An examination of the cytotoxic effects of silica on macrophages. J Exp Med 1966; 124:141-54.

10 Benson SC, Belton JC, Scheve LG. Regulation of lung fibroblast proliferation and protein synthesis by bronchiolar lavage in experimental silicosis. Environ Res 1986;41:61-78.

11 Gross P, deTreville RTP. Alveolar proteinosis: its experimental production in rodents. Archives of Pathology 1968;86:255-61.

12 Schuyler M, Gauner HR, Stankus RP, Kaimal V, Hoffman E, deSalvaggio J. Bronchoalveolar lavage in silicosis. Lung 1980; 157:95-102.

13 Kawada H, Horiuchi T, Shannon JM, Kuroki Y, Voelker DR, Mason JR. Alveolar type II cells, surfactant protein A (SP-A), and the phospholipid components of surfactant in acute silicosis in the rat. Am Rev Respir Dis 1989;140:460-70.

14 Laurell C-B. Electroimmunoassay. Scand J Clin Lab Invest 1972;29(suppl 124):21-37.

15 Blaschke E, Eklund A, Hernbrand R. Determination of fibronectin and its degradation products in bronchoalveolar lavage fluid. Scand J Clin Lab Invest 1990;50:629-34.

16 Engström-Laurent A, Laurent UBG, Lilja K, Laurent TC. Concentration of sodium hyaluronate in serum. Scand J Clin Lab Invest 1985;45:497-504.

17 Casarett-Bruce M, Camner P, Curstedt T. Changes in pulmonary lipid composition of rabbits exposed to nickel dust. Environ Res 1981;26:353-62.

18 Bartlett GR. Phosphorus assay in column chromatography. J Biol Chem 1959;234:466-8.

19 Donaldson K, Brown GM, Brown DM, Slight J, Robertson
MD, Davis JM. Impaired chemotactic responses of bronchoalveolar leukocytes in experimental pneumoconiosis. J Pathol 1990;160:63-9.

20 Struhar D, Harbeck RJ, Mason RJ. Lymphocyte populations in lung tissue, bronchoalveolar lavage fluid, and peripheral blood in rats at various times during development of silicosis. Am Rev Respir Dis 1989;139:28-32.

21 Eklund A, Blaschke E. Relationship between changed alveolarcapillary permeability and angiotensin-converting enzyme activity in serum in sarcoidosis. Thorax 1986;41:629-34.

22 Rennard SI, Hunninghake GW, Bitterman PB, Crystal RG. Production of fibronectin by the human alveolar macrophage: Mechanism for the recruitment of fibroblasts to sites of tissue injury in interstitial lung diseases. Proc Natl Acad Sci USA 1981;78:7147-51.

23 Czop JK, McGowan SE, Center DM. Opsonin-independent phagocytosis by human alveolar macrophages: augmentation by human plasma fibronectin. Am Rev Respir Dis 1982;125: 607-9.

24 Håkansson $L$, Venge $P$. The combined action of hyaluronic acid and fibronectin stimulates neutrophil migration. J Immunol 1985;135:2735-9.

25 Postletwhaite AE, Keski-Oja J, Balian G, Kang AH. Induction of fibroblast chemotaxis by fibronectin. J Exp Med 1981; 153:494-9.

26 Bitterman PB, Rennard SI, Adelberg S, Crystal RG. Role of fibronectin as a growth factor for fibroblasts. J Cell Biol 1983;97:1925-32.

27 Nettelbladt O, Tengblad A, Hällgren R. Accumulation of hyaluronan (hyaluronic acid) in lung tissue during experimental alveolitis parallels development of interstitial edema. Am J Physiol 1989;257;1:L379-89.

28 Nettelbladt O, Hällgren R. Hyaluronan (hyaluronic acid) in bronchoalveolar lavage fluid during the development of bleomycin-induced alveolitis in the rat. Am Rev Respir Dis 1989;140:1028-32.

Accepted 18 March 1991 